\title{
Effect of Process Parameters on Micro Hardness of Mild Steel Processed by Surface Grinding Process
}

\author{
Balwinder Singh $^{1}$, Balwant Singh ${ }^{2}$ \\ ${ }^{1}$ (Department of Mechanical Engineering, GZS Punjab Technical University Campus Punjab 151001, India \\ ${ }_{2}^{2}$ (Department of Mechanical Engineering, GZS Punjab Technical University Campus Punjab 151001, India
}

\begin{abstract}
Surface grinding process can be utilized to create flat shapes at a high production rate and low cost.. In this investigation, indigenously designed set up were used for evaluating the surface grinding process was established. An experimental investigation was carried out to study the effect of surface grinding process parameters i.e. Inlet pressure of coolant, grinding wheel speed, work-piece speed, and nozzle angle on the micro hardness of the mild steel specimen. In the present study Horizontal spindle and reciprocating table type surface grinding machine fitted with test rig is used and cutting fluid is applied through the convergent nozzle to throw the cutting fluids at the cutting zone. In order to evaluate the effect of selected process parameters, one variable approach has been used in the present study. Plots of various Micro Hardness responses have been used to determine the relationship between the output response and the input parameters. The value of microhardness of grinded mild steel work-piece varies from 292.63 to $370.73 \mathrm{HV}$.
\end{abstract}

Keywords: Surface grinding process, Micohardness, Mild Steel Specimen

\section{INTRODUCTION}

The grinding process is the material removal and surface process to shape the finish part of any materials example steel, aluminum alloys and the others. Microhardness plays a significant role in determining and evaluating the surface quality of a product as it affects the functional characteristic. The product quality depends very much on microhardness. Decrease of microhardness also leads to decrease of product quality. In field of manufacture, especially in engineering, the microhardness can be a considerable importance that can affects the functioning of a component and the microhardness measurements can provide information about the material as a general quality control of material after grinding. The importance of microhardness produced during grinding with the change in parameters gives reprove of a material's properties, such as ductility and wear resistance.

\section{GRINDING PROCESS AND GRINDING FLUID APPLICATION}

Grinding developed as a metal manufacturing process in the nineteenth century. Surface grinders produce flat surfaces. The measurement of microhardness depends on the type of material, dimension of the part and its state. The main roles of cooling fluids are to swiftly remove heat from the grinding zone and to wash out the grinding chips. Grinding played an important role in the development of tools and in the production of steam engines, internal combustion engines, bearings, transmissions, and ultimately jet engines, astronomical instruments, and micro-electronic devices [1]. While, the microhardness also contributed an importance factor in the industry. Microhardness form is an important surface integrity characteristic as it is last tooling operation. On the other hand, grinding causes variation in microhardness along the depth of ground sample. Moorthy et al. [2] pointed out that thermoplastic deformation during grinding results in the conversion of retained austenite to martensite by alteration of microstructure. These metallurgical transformations also affect microhardness profile. Surface grinding is frequently applied to match dimensional tolerance during the manufacturing of structural components. However, improper grinding can result is surface cracks and sub-surface flaws. Tawakoli et al., reviewed dry grinding process as it is one of the most favorable processes from an economical as well as an ecological point of view [3]. Oliveira et al. analyzed relevant industrial demands for grinding research [4]. The focus was to understand the main research challenges in the extensive industrial use of the process. Kiyak et al., examined and compared dry and cutting fluid application (wet) in grinding as the process is practiced to obtain the best possible surface quality and dimensionally accurate of ground machine parts [5]. The application of cutting fluid is generally carried out and the influence of selected cutting fluid on surface roughness is widely accepted positive. The mean size of abrasive particle used in each tool determines the rate at which it will cut, and the quality of surface finish it will provide. Cakir et al. analyzed that effect of friction generated heat affects shorter tool life, higher surface roughness and lowers the dimensional sensitiveness of work material [6]. They reported different methods to protect cutting tool from the generated heat during machining operations to provide lubrication and cooling effects between cutting tool and work-piece. The selection of cutting fluids should be carefully carried out to obtain optimum result in machining processes. Various factors affects the 
selection of cutting fluid type in machining operation such as type of work-piece materials, cutting tool material and the method of machining processes. Water was used as cutting fluid for grinding mild steel in the present study. New nozzle designs were presented that give long coherent jets, up to $45 \mathrm{~m} / \mathrm{s}$, maximizing the application of fluid into the grinding zone [7]. The surface irregularities of work piece are compressed by the application of a grinding force. Grinding operation generates excessive heat in grinding zone that leads to elevated temperature condition. This elevated temperature condition followed by rapid cooling action of coolant induces plastic deformation at various degrees along the depth of ground surface. A principal function of fluid is to improve lubrication and subsequently reduce the risk of thermal damage and improve process performance [8].

\section{PARAMETERS UNDER INVESTIGATION AND THEIR LEVELS}

Using cause and effect analysis the factors which may affect the response parameters (micro hardness, surface roughness and dimensional control) with their levels were identified. Some factors like type of coolant, work-piece material, nozzle tip distance and grade of grinding wheel were kept constant during the experimental study.

Table 1: Selected process parameters and their levels

\begin{tabular}{|l|l|l|l|}
\hline \multirow{2}{*}{ Parameters } & Levels & Level-2 & Level-3 \\
\cline { 2 - 4 } & Level-1 & 3718 & 5670 \\
\hline Wheel peripheral speed $(\mathrm{m} / \mathrm{sec})$ & 2800 & 3 & 4.5 \\
\hline Work-Table speed $(\mathrm{m} / \mathrm{minute})$ & 1.5 & 27 & 29 \\
\hline Inlet pressure of coolant $\left(\mathrm{kg} / \mathrm{cm}^{2}\right)$ & 25 & 8 & 12 \\
\hline Nozzle angle (degrees) & 6 & 3 & 9 \\
\hline
\end{tabular}

The various parameters like wheel speed, work-piece speeds were selected as per availability of pulley combinations on grinder. The inlet pressures were then selected so that velocity of the fluid at the outlet maintains proper cooling. Finally the various nozzle angles were selected at which the cooling effect and nozzle efficiency is optimal as claimed by various researchers in the available literature. The internal geometry of nozzles was selected as proposed by various researchers [8]. The lists of parameters studied with their levels are shown in the Table 1.

\section{EXPERIMENTAL DETAILS}

The experiments have been conducted on modified surface grinding machine (Make: HMT; Model: (GTC- 28) available at Central Workshop, GZS PTU Campus, Bathinda. The speeds of wheel were changed by changing the position of V-Belts for different combinations of pulleys available on the machine and the speeds of work-table were changed by adjusting the knob at already marked positions. The other main components of experiment set up are as given below. Convergent nozzle was selected as shown in fig 1. By taking the same dimensions as per design of the nozzle was made from aluminum rod of $42 \mathrm{~mm}$ diameter. The nozzle was manufactured by boring operation of $7 \mathrm{~mm}$ diameter and finally the inside is finished by using the tool having the shape exactly that of internal geometry of nozzle. The other parts are as given below.

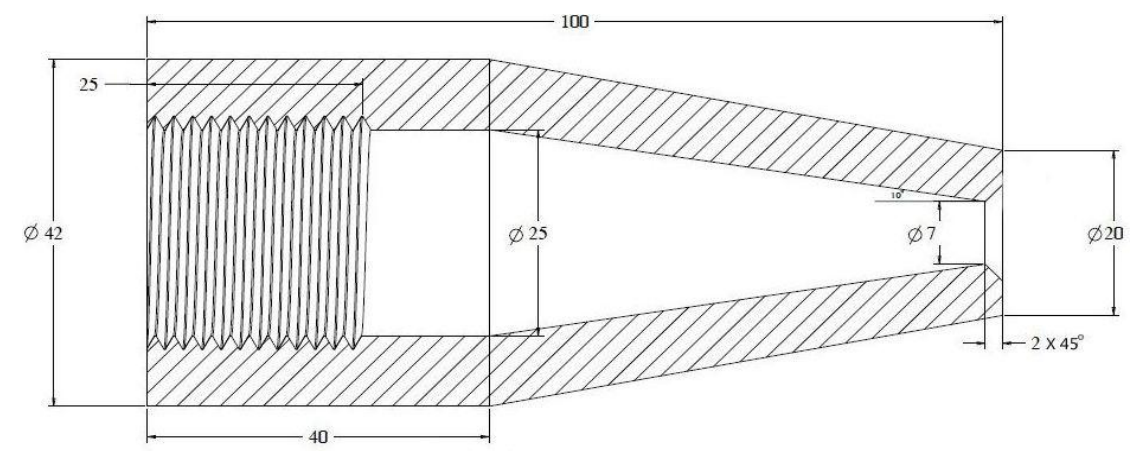

Fig.: 1 Convergent nozzle

\section{a ) Centrifugal Pump: -}

To pump the coolant flow to the required pressure $1.5 \mathrm{hp}$ centrifugal pump was used. The fluid pressure is controlled with the help of a pressure regulating valve.

b) Pressure gauge: - 
Pressure is measured with the help of pressure gauge $\left(0-30 \mathrm{~kg} / \mathrm{cm}^{2}\right.$ range $)$

c) Coolant Tank:-

A sump tank of capacity 100 liters was used, from where pump sucks the coolant and after performing the cooling action it again gets collected in it after filtering the chips.

\section{d). Protractor: -}

Nozzle angle with the horizontal was changed using screw arrangement and the angle was measured on the protractor with different angles marked on it. Before starting the experiments the grinding wheel was balanced to avoid vibration if any and it was dressed using dressing tool.

\section{e). Speed Set-Up:-}

The speed of the wheel was changed by changing the position of $\mathrm{V}$ - belts on various pulley combinations available on the machine. The speeds of work -table were changed by adjusting the knob at already marked positions. The nozzle tip distance is varied with the help of screw arrangement.

\section{Experimentation}

Three pieces of dimension $75 \times 50 \mathrm{~mm}$ were cut from $10 \mathrm{~mm}$ thick mild steel flat with the help of power hacksaw. They were firstly rough ground on the surface grinder to reduce their thickness to $9.1 \mathrm{~mm}$ and then they were finally finished to the required thickness of $9 \mathrm{~mm}$ on surface grinder. On each work-piece three cuts were applied. The two cuts were of 50 microns each .and one cut was made with coolant throw on work-piece. Convergent nozzle was selected, by taking the same dimensions as per drawing of the nozzle was made from aluminum rod. For pumping the coolant to the required pressure $1.5 \mathrm{hp}$ centrifugal pump was used. The fluid pressure is controlled with the help of a pressure regulating valve and the pressure is measured with the help of pressure gauge. A sump tank of capacity 100 litres was used, from where pump sucks the coolant and after performing the cooling action it again gets collected in it after filtering the chips. Eighteen pieces were made on wire cut Machine. Nine pieces were made to check the dimensional accuracy and nine pieces were made on polishing machine with different grade of emery paper to check the Micro hardness of Specimens sample available in EMM laboratory of Giani Zail Singh PTU Campus Bathinda.

The three values of nozzle angle were selected are given in Table 1. The schematic of Experimental set up arrangement is shown in fig. 2 in which the provision to change nozzle angle was made. The speed of the work piece table is varied by adjusting the knob of the hydraulic system. The values of the input process parameters are changed as per design of experiment for the Grinding.

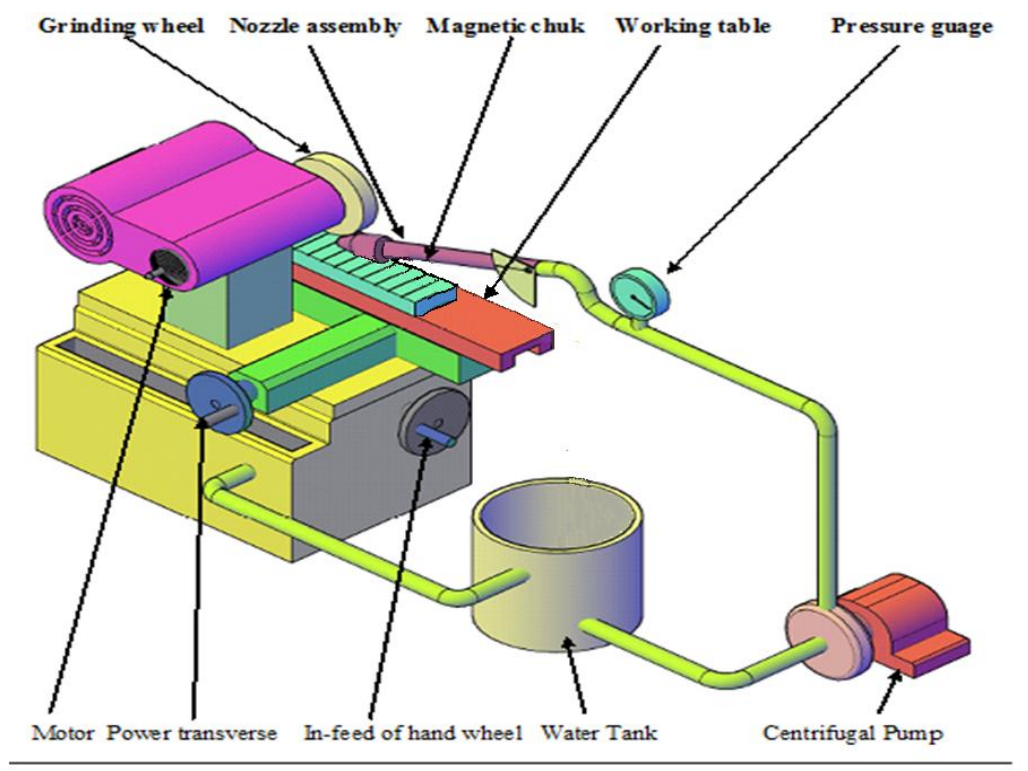

Fig: 2: Experimental set up and its arrangement

\section{Measurement Of Micro-Hardness}

Micro hardness tests were conducted on the micro hardness tester ; Make: Meta tech industries, Pune, India; Model: MVH-I). Micro hardness measured is dependent on the diameter of indentation on the samples. The indents formed by pyramid shaped indenter were measured using the scale on the machine which had loaded software in it that converts the disancet between the coordinates into micro hardness of the sample. There are two eyepieces available in the instrument of $10 \mathrm{X}$ and 40X. Eyepiece of 10X was used for the experiments. 
The diameter of indent was measured, which gives the direct number for micro hardness. Load applied and dwell time for micro hardness testing was taken as 1000 grams and 20 seconds respectively. Measurements were done in EMM Laboratory of Giani Zail Singh PTU Campus Bathinda. Results of main effects Inlet pressure of coolant, grinding wheel speed, work-piece speed, and nozzle angle on the micro hardness of the mild steel specimen are shown as bar charts in fig 3, fig 4, fig 5 and fig 5 respectively.

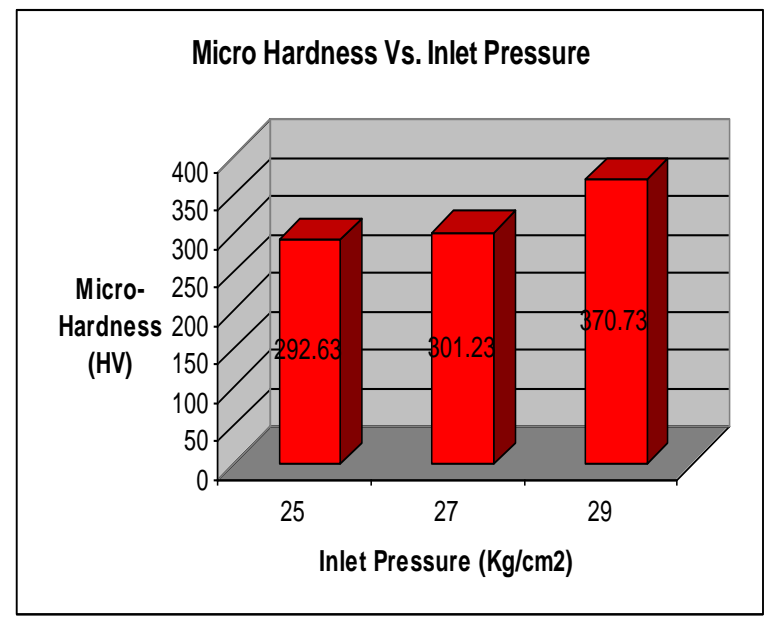

Fig 3: Main effect of inlet pressure on microhardness.

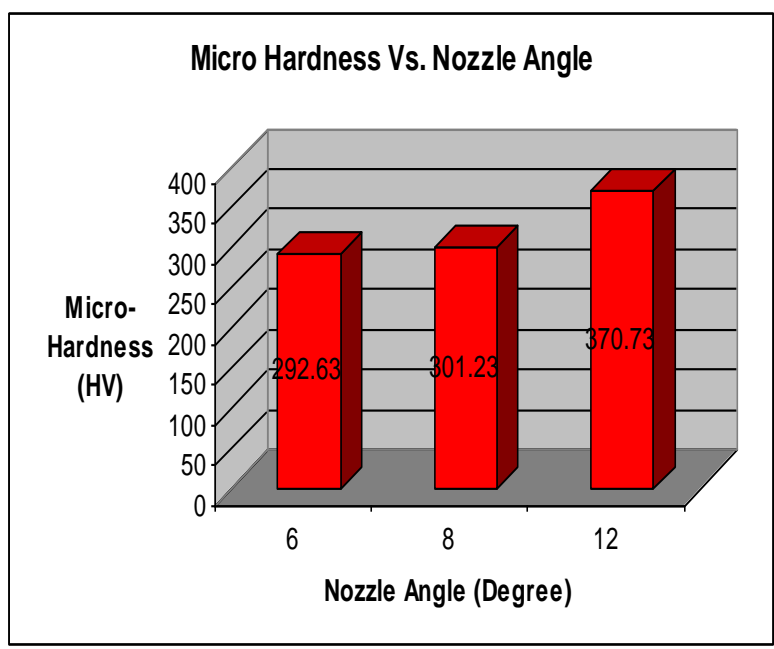

Fig 5: Main effect of nozzle angle on micohardness.

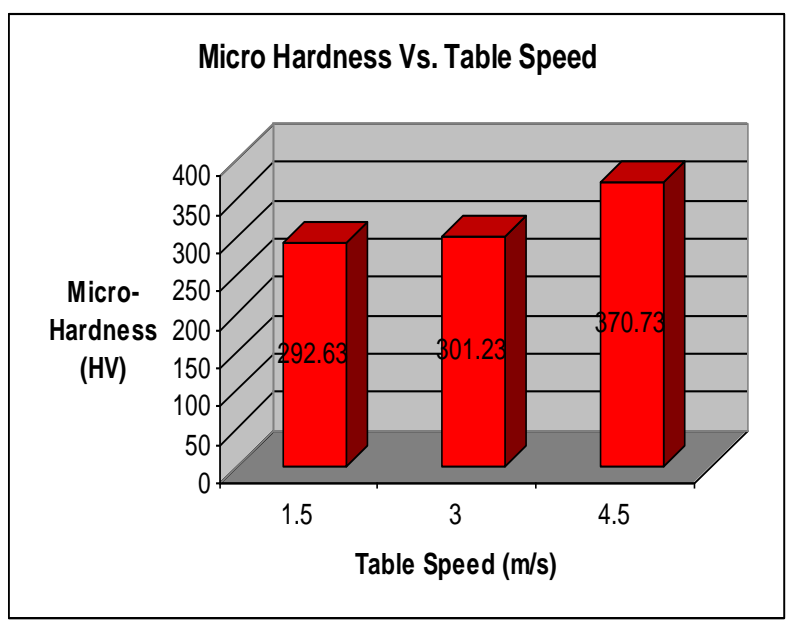

Fig 4: Main effect of table speed on micohardness.

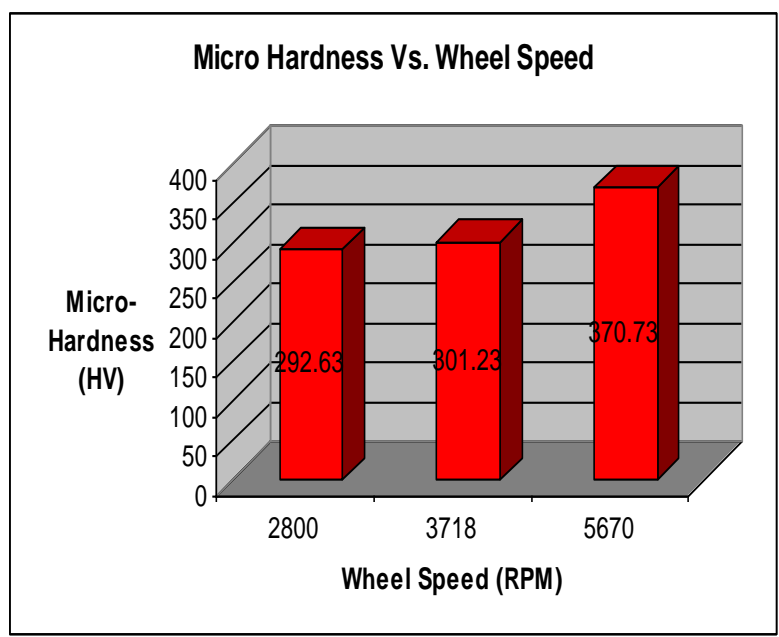

Fig 6: Main effect of wheel speed on micohardness.

\section{Conclusions}

The following are the conclusions drawn from the present experimentation

1. The investigation of the surface grinding process parameters shows that all the selected parameters i.e. inlet pressure of coolant, grinding wheel speed, and table speed and nozzle angle have affect on the micohardness of the finished mild steel work-piece.

2. The value of micohardness of grinded mild steel work-piece varies from 292.63 to $370.73 \mathrm{HV}$. The value of Minimum micohardness $292.63 \mathrm{HV}$. is obtained as per set of parameters given below:

Inlet coolant pressure $25 \mathrm{~kg} / \mathrm{cm}^{2}$, Wheel speed $2800 \mathrm{RPM}$, Work piece speed $1.5 \mathrm{~m} / \mathrm{min}$ and Nozzle angle $6^{\circ}$

\section{REFERENCES}

[1] H. Z. Choi, S. W. Lee, D. J. Kim, Optimization of cooling effect in the grinding with mist type coolant, American Society for Precision Engineering Proceedings, Crystal City, Virginia, November 2001.

[2] V. Moorthy, B. A. Shaw, P. Mountford, and P. Hopkins, "Magnetic Barkhausen emission technique for evaluation of residual stress alteration by grinding in case-carburised En36 steel," Acta Materialia, vol. 53, no. 19, pp. 4997-5006, 2005.

[3] J.A. Webster, C. Cui, R.B. Mindek Jr. and Dr. R. Lindsay, Grinding fluid application system design, CIRP Annals - Manufacturing Technology, Volume 44, Issue 1, pp. 333-338, 1995.

[4] J.F.G. Oliveira, E.J. Silva, C. Guo and F. Hashimoto, Industrial challenges in grinding, CIRP Annals - Manufacturing Technology,Volume 58, Issue 2, pp. 663-680, 2009. 
[5] Murat Kiyak and Orhan Cakir, Study of surface quality in dry and wet external cylindrical grinding, International Journal of Computational Materials Science and Surface Engineering, Volume 3, Issue 1, pp. 12-23, 2010.

[6] O. Cakir, A. Yardimeden, T. Ozben and E. Kilickap, Selection of cutting fluids in machining processes, Journal of Achievements in Materials and Manufacturing Engineering, Volume 25, issue 2, pp. 99-102, December 2007.

[7] T. Tawakoli, A. Rasifard and M. Rabiey, High-efficiency internal cylindrical grinding with a new kinematic, International Journal of Machine Tools and Manufacture, Volume 47, Issue 5, pp. 729-733, April 2007.

[8] V.A. Baines-Jones, M.N. Morgan, D.R. Allanson, A.D.L Batako, Grinding fluid delivery system design-Nozzle Optimization, European Research Council Grant No: GR/S82350/01. 